Disclaimer: This is a machine generated PDF of selected content from our products. This functionality is provided solely for your convenience and is in no way intended to replace original scanned PDF. Neither Cengage Learning nor its licensors make any representations or warranties with respect to the machine generated PDF. The PDF is automatically generated "AS IS" and "AS AVAILABLE" and are not retained in our systems. CENGAGE LEARNING AND ITS LICENSORS SPECIFICALLY DISCLAIM ANY AND ALL EXPRESS OR IMPLIED WARRANTIES, INCLUDING WITHOUT LIMITATION, ANY WARRANTIES FOR AVAILABILITY, ACCURACY, TIMELINESS, COMPLETENESS, NON-INFRINGEMENT, MERCHANTABILITY OR FITNESS FOR A PARTICULAR PURPOSE. Your use of the machine generated PDF is subject to all use restrictions contained in The Cengage Learning Subscription and License Agreement and/or the Gale Academic OneFile Terms and Conditions and by using the machine generated PDF functionality you agree to forgo any and all claims against Cengage Learning or its licensors for your use of the machine generated PDF functionality and any output derived therefrom.

\title{
Multiscale habitat characterization of herbaceous Atlantic Coastal Plain Flora on lakeshores in Nova Scotia
}

Authors: Natasha Daze Querry, Xavier Bordeleau, Karen A. Harper and Sean P. Basquill Date: June 2017

From: Botany(Vol. 95, Issue 6)

Publisher: NRC Research Press

Document Type: Report

Length: 6,708 words

DOI: http://dx.doi.org/10.1139/cjb-2016-0267

Abstract: Atlantic Coastal Plain Flora (ACPF) are a group of plants mostly inhabiting lakeshores along the Atlantic coast of the United States, with disjunct populations in Nova Scotia and Ontario. To better define their ecological requirements, the main objective of this study was to determine the factors (biotic and abiotic habitat components) influencing ACPF communities (distribution, species abundance, and richness) at both the landscape and local scales. On 16 lakeshores in southwestern Nova Scotia, we characterized ACPF communities and habitat within $20 \mathrm{~cm}$ square contiguous quadrats distributed along $20 \mathrm{mtransects} \mathrm{(landscape} \mathrm{scale)} \mathrm{and} \mathrm{in} 5 \mathrm{~m} \times 5 \mathrm{mgrids}$ (local scale). Performing redundancy analysis ( $\mathrm{n}=16$ transects), we found that at the landscape scale, shoreline slope and shrub species distribution influenced the quantity of suitable habitat available for ACPF, with mineral shorelines supporting higher ACPF richness. Using spatial generalized linear mixed models $(n=3125$ quadrats in five grids), we found that elevation, vegetation elements (shrubs, sundews, graminoids), and substrate type mostly influenced ACPF presence and abundance. ACPF also showed inter-specific differences in habitat preferences. Defining ACPF ecological requirements at both the landscape and local scales is important to guide conservation and management actions in Nova Scotia and throughout their North American range.

Key words: lakeshore, scale, hydrological disturbances, elevation, substrate.

Resume : La Flore de la Plaine Cotiere Atlantique (FPCA) consiste en un groupe de plantes qui habitent principalement les berges de lacs le long de la cote Atlantique des Etats-Unis, comprenant des populations disjointes en Nouvelle-Ecosse et en Ontario. Afin de mieux definir leurs exigences ecologiques, le but principal de cette etude etait de determiner quelles composantes d'habitat (biotiques et abiotiques) influencent les communautes de FPCA a l'echelle du paysage et localement. Nous avons caracterise les communautes de FPCA et leur habitat sur 16 berges de lacs dans le sud-ouest de la NouvelleEcosse dans des quadrats de $20 \mathrm{~cm}$ carre, distribues le long de transects de $20 \mathrm{~m}$ (echelle du paysage) et a l'interieur de grilles de $5 \mathrm{~m} \times 5 \mathrm{~m}$ (echelle locale). En realisant des analyses de redondance ( $n=16$ transects), nous avons trouve qu'a l'echelle du paysage, la pente de la berge ainsi que la distribution d'especes ligneuses influencaient la quantite d'habitat disponible pour les FPCA, alors que les berges minerales supportaient une plus grande richesse de FPCA. En utilisant des modeles mixtes lineaires generalises ( $n=3125$ quadrats), nous avons trouve que l'elevation, la vegetation (especes ligneuses, droseras, graminees) et le type de substrat ont principalement influence la presence et l'abondance des FPCA. Les FPCA ont aussi montre des differences interspecifiques dans leurs preferences d'habitat. II est important de definir les exigences ecologiques des FPCA a l'echelle du paysage et localement pour guider les actions de conservation et de gestion en NouvelleEcosse et a travers leur distribution en Amerique du Nord.

Mots-cles : berges de lacs, echelle, perturbations hydrologiques, elevation, substrat.

Introduction

Species distributions are largely determined by habitat suitability, dispersion barriers, and (or) stochastic factors (Williams et al. 2009). Although species distributions can be defined at landscape scales (e.g., watersheds), understanding habitat occupancy at local scales (e.g., habitat patches) is also essential for determining species habitat requirements (Williams et al. 2009). At regional and landscape scales, climate and indirect factors (e.g., transport of materials) are among the most important influences on plant species composition, whereas at local scales, direct factors (e.g., light, temperature, water) and stochastic factors (e.g., mortality, predation) are stronger determinants of plant distributions (Kembel and Dale 2006; Marchand and Houle 2006; Rooney and Bayley 2011). Moreover, the distributions of many species are affected by interactions between these landscape and local-scale environmental factors (Parviainen et al. 2008)

For lakeshore plant communities, watershed area is an important driver of species composition at the landscape scale, through its influence on the amplitude of hydrological disturbances, such as water level fluctuations, flooding, ice scouring, and wave action (Hill and Keddy 1992; Morris et al. 2002). According to Hill and Keddy (1992), watershed area could be used as a proxy to characterize hydrological disturbances instead of the actual events, which exhibit substantial seasonal and annual variation. Water levels fluctuate annually because of variability in rainfall and evaporation patterns, which affect the timing, duration, and number of flood events (Nilsson and Wilson 1991). Even small changes in water levels affect the germination of many lakeshore plant species (Moore and Keddy 1988; Keddy and Sharp 1994). Ice scouring and wave action are also critical disturbances on lakeshores; the former creates substrate heterogeneity and improves colonization of nearby shorelines (Day et al. 1988; Sweeney and Ogilvie 1993; Holt et al. 1995; Hill et al. 1998), whereas the latter physically removes plant biomass and washes nutrients and fine sediments, reducing soil fertility (Keddy 1985; Wilson and Keddy 1986).

At local scales, lakeshore vegetation varies along two major ecological gradients, water depth and soil fertility, both of which are strongly shaped by shoreline topography (shoreline slope) and exposure to wave action (shoreline aspect) (Keddy 1983; Weiher and Keddy 1999). The variation in moisture levels, nutrient content, and soil particle size composition along these two gradients (Keddy and Reznicek 1982; Keddy 1983) creates a variety of niches across the riparian zone. The position of plant species on lakeshores mainly depends on their individual competitive abilities and levels of soil organic matter (Wilson and Keddy 1986); winter inundation and summer drawdown, which determine the flooding regime and soil saturation (Sorrie 1994), 
As lakeshores are exposed to stress (e.g., soil infertility, flooding) and disturbances (e.g., ice scouring, wave action), they provide typical habitat for plant species that have broad environmental tolerances but poor competitive abilities, such as many herbaceous Atlantic Coastal Plain Flora (ACPF) species (Wisheu and Keddy 1989). ACPF are a group of taxonomically unrelated plants species that share common habitats (e.g., lakeshores, wetlands) along the Atlantic coastal plain physiographic region of USA with disjunct populations in Nova Scotia and Ontario (Wisheu and Keddy 1989, 1994; Sweeney and Ogilvie 1993). As increasing development threatens the US populations (Francis and Munro 1994), southwestern Nova Scotia supports some of the last large ACPF populations in the world, and most of the suitable remaining habitat for ACPF species (Wisheu et al. 1994; Morris et al. 2002).

Knowledge gaps, such as our ecological understanding of key habitat characteristics, have restricted the establishment and implementation of strategic conservation plans for the preservation of ACPF populations in Nova Scotia (Environment Canada and Parks Canada Agency 2015). As riparian communities are driven by both landscape- and local-scale factors (von Behren et al. 2013), a multiscale approach is essential to address the knowledge gaps and to define specific ecological requirements for ACPF communities (Environment Canada and Parks Canada Agency 2015). ACPF communities are known to be influenced by regional and landscape-scale habitat components: climate and physiography (Sweeney and Ogilvie 1993; Sorrie 1994; Clayden et al. 2010), land use, watershed and lake area, and shoreline aspect and slope (Keddy 1984, 1985; Wilson and Keddy 1986; Holt et al. 1995; Morris et al. 2002). However, it remains unclear how various components of ACPF communities and landscape-scale characteristics interact.

At a finer scale, ACPF are also known to be associated with local-scale habitat characteristics, such as gravel and cobble substrates, sundews, and absence of shrubs (Wisheu and Keddy 1989; Wisheu et al. 1994). However, the significance and amplitude of their relationship have not been extensively quantified in regards to the abundance and richness of ACPF at very fine scales (e.g., an area [less than or equal to]20 [cm.sup.2]). We hypothesized that the cover of other functional groups of plants and structural elements of lakeshores influence ACPF communities at a local scale. Combining community and individual level assessments would allow an overall evaluation of habitat preferences of ACPF while accounting for differences in individual species requirements. Whereas habitat characteristics of individual ACPF species have previously been defined, the assessment was limited to rare species or species at risk (Environment Canada and Parks Canada Agency 2015). However, knowledge of the habitat requirements of common ACPF is essential because these species can serve as diagnostics of entire ACPF communities, and thus provide a more complete understanding of suitable habitat for endangered, ephemeral, and rare ACPF species.

Consequently, our objectives were: (i) to determine the factors influencing the width of the ACPF zone on lakeshores, ACPF richness, and ACPF abundance at multiple landscape scales (i.e., watershed, lake, and shoreline levels) using topographic and inferred hydrological disturbance variables; and (ii) to determine the factors influencing ACPF presence (for all species together and for five abundant individual species), ACPF richness, and ACPF abundance at a local scale using substrate type, fine elevation measurements (centimetres in height above the waterline), and the cover of the different structural elements of the vegetation.

Materials and methods

Study area

This study was conducted in southwestern Nova Scotia, a region with several watersheds where numerous ACPF species and critical habitats have been identified (Francis and Munro 1994). Southwestern Nova Scotia is generally characterized by sandy acidic soils with mixed drainage and a very humid climate (Sweeney and Ogilvie 1993). Mean daily temperature ranges from -5 [degrees]C in January to 19 [degrees]C in July, and monthly precipitation ranges from 96 to $165 \mathrm{~mm}$ in nearby Bridgewater (Climate Canada 2015). The vegetation is dominated by coniferous tree species, although forest stands along lakeshores support a mixture of coniferous and deciduous tree species, including red maple (Acer rubrum L.), beech (Fagus grandifolia Ehrh.), yellow birch (Betula alleghaniensis Britton), and red spruce (Picea rubens Sarg.). In wetter habitats, common woody shrub species include sweet gale (Myrica gale L.), smooth witherod (Viburnum nudum L.), and Canada holly (llex verticillata (L.) A. Gray) (Sweeney and Ogilvie 1993)

Sampling design and data collection

We first chose lakes with higher documented numbers of ACPF species, located within the Medway and Mersey watersheds. The Medway watershed is a high priority watershed for ACPF conservation planning (Environment Canada and Parks Canada Agency 2015) and is the second most important site for ACPF in Nova Scotia (Sweeney and Ogilvie 1993). We then listed ACPF species found on each lake using the ACPF database from the Mersey Tobeatic Research Institute (2015), and selected 10 provincially common and (or) abundant herbaceous species, as herbaceous species are a major component of ACPF lakeshore communities and have similar habitat preferences (Table 1). Lastly, we identified seven lakes that supported the highest number of our preselected ACPF species, and located between one and five sites per lake for a total of 16 sites (Fig. 1) using the following criteria: high ACPF abundance/richness, wide west or southwest facing shorelines, and site accessibility.

At each site, we established one $20 \mathrm{~m}$ transect perpendicular to the waterline, which we divided into $0.2 \mathrm{~m} \times 0.2 \mathrm{~m}$ contiguous quadrats (100 quadrats per transect) (Fig. 2). The starting position of each transect was located where vegetation emerged, and the transect extended to at least $5 \mathrm{~m}$ beyond the forest edge. Transects were sampled between mid-June and mid-July 2015. In addition to transect sampling, we also used a two-dimensional sampling approach to capture the within shoreline gradients and to collect more data on ACPF habitat. For this approach, we selected five sites on five different lakes based on the transects with the highest ACPF richness and the widest shorelines (Fig. 1). At each of these five sites, we established a 5 $\mathrm{m} \times 5 \mathrm{~m}$ grid, centred on the transect, starting on the lakeside boundary of emergent vegetation and extending towards the forest edge. The grids were divided into $0.2 \mathrm{~m} \times 0.2 \mathrm{mcontiguous}$ quadrats ( 625 quadrats per grid) and sampled from midAugust to the beginning of September 2015 .

Within each quadrat along the transects and in the grids, we visually estimated the cover of the 10 preselected herbaceous ACPF and different vegetation elements using cover classes of $<5 \%, 6 \%-25 \%, 26 \%-50 \%, 51 \%-75 \%$, and $>75 \%$. These vegetation elements included: litter (dead needles and leaves), woody material (pieces of bark, tree and shrub branches), bryophytes, graminoids, sundews (Drosera intermedia Hayne and Drosera rotundifolia L.), ferns, and deciduous/coniferous woody species, for which we estimated cover for every $0.2 \mathrm{~m}$ height interval up to $2 \mathrm{~m}$. We also assessed the main physical substrate using particle size classes for mineral soil: sand $(0.005-0.2 \mathrm{~cm})$, gravel $(0.2-7.5 \mathrm{~cm})$, cobble $(7.6-25 \mathrm{~cm})$, stone $(26-60$ $\mathrm{cm}$ ), or boulders $(>60 \mathrm{~cm}$ ) (Keys et al. 2010). When algae, litter, or peat material covered most of the quadrat $(>50 \%)$, we characterized the main substrate as organic. For each quadrat along the transects, we measured the difference in elevation with the previous quadrat using a level and a ruler.

[FIGURE 1 OMITTED]

Data analysis 
To address our first objective, we defined landscape-scale habitat characteristics as features expressed at the watershed, lake, and shoreline levels using our transect data. For the 16 transects distributed on seven lakes, we calculated lake and tertiary watershed areas using the Nova Scotia Forest Inventory--Geographic Information Systems data (Nova Scotia Department of Natural Resources 2013). Some lakes were in the same watershed, owing to their physical proximity (Cameron and Ponhook Lake, Hog and Molega Lake). We calculated the transect slope by dividing the difference in elevation between the first and last quadrat by the transect length and the distance to shrub as the distance from the waterline to the beginning of continuous woody species presence (the first quadrat containing $>3 \%$ cover of shrubs). Shoreline type was defined as organic when $>50 \%$ of the quadrats on lakeshores were dominated by organic matter or mineral substrate.

We described ACPF communities at the transect level using ACPF zone width, abundance, and richness. Cover classes of the 10 pre-selected ACPF species were first converted to their midpoint values ( $3 \%, 16 \%, 38 \%, 63 \%$, and $88 \%)$ and then summed in all quadrats along a single transect for the ACPF abundance. ACPF richness was determined as the number of pre-selected ACPF species present. We also calculated ACPF zone width (an index of the quantity of suitable habitat available to ACPF species along the lakeshore-to-forest gradient) as the distance from the beginning of the transect (waterline) to the last preselected ACPF individual.

To test the hypothesis that herbaceous ACPF communities (ACPF zone width, ACPF abundance, and ACPF richness) are influenced by landscape-scale habitat characteristics (watershed area, lake area, slope, distance to shrub, and shoreline type), we performed redundancy analysis (RDA) ordination (vegan package; Oksanen et al. 2015) in R 3.2.2. (R Core Team 2015). $\mathrm{RDA}$ is an extension of principal component analysis that explicitly models response variables as a function of explanatory variables by assessing the statistical significance of linear relationships using permutation tests (Zuur et al. 2007). We used a log-transformation to reduce the asymmetry in the skewed distribution of ACPF abundance data. Based on the correlation matrices, we performed the permutation test with 9999 iterations to test the validity of the null hypothesis that no linear relationship exists between components of ACPF communities (unconstrained matrix) and landscape-scale habitat characteristics (constrained matrix). The permutation test, computed with the ANOVA function, allowed us to compare the observed relationship (between the unconstrained and constrained matrices) with the randomly permuted relationships resulting from randomizing the rows of the unconstrained matrix. For the purpose of our study, we included all five explanatory variables in our final model. We did not consider the nested effect in the RDA (transects nested within lakes) because of the high intralake variability in the three response variables considered, as well as our limited sample size and problems associated with multilevel modelling in this context (Maas and Hox 2005).

\section{[FIGURE 2 OMITTED]}

Local-scale habitat characteristics

To address our second objective, we defined local-scale habitat characteristics as features expressed at the quadrat leve using our grid data ( $n=3125$ quadrats). To quantify the abundance of different functional group of plants for each quadrat, we used the cover of ferns, shrubs, sundew, graminoids, and bryophytes. We summed fern and shrub covers (deciduous/coniferous woody species) that were initially quantified at height intervals of $0.2 \mathrm{~m}$. We also investigated the influence of the cover of litter and woody material, physical substrate (categories of sand, gravel, cobble, stone, boulder, and organic), and elevation above the waterline. The change in elevation from the lakeshore to the forest edge was determined along the middle line of each grid, where we calculated the difference in elevation of each quadrat relative to the first quadrat (waterline). Explanatory variables were checked for collinearity $(r<0.43)$. Only elevation and shrub cover had higher correlation at $r=0.56$; however, both variables were kept in the model because of their different biological implications (proximity to hydrological processes versus competition).

To describe ACPF communities at the quadrat level, we calculated the total cover of all pre-selected ACPF species and the total number of ACPF species in each quadrat, defined as ACPF abundance and ACPF richness, respectively. We also assigned the value of 1 or 0 for the presence or absence of ACPF species within each quadrat, as well as for the five most common ACPF species (presence in $>500$ quadrats) to evaluate differences in interspecific habitat requirements among ACPF species.

To test the hypothesis that herbaceous ACPF presence, abundance, and richness are influenced by local-scale habitat characteristics (elevation, shrubs, sundews, graminoids, bryophytes, ferns, litter, woody material, substrate), we performed spatial generalized linear mixed models (GLMMs). GLMMs are known for their flexibility in accounting for spatial autocorrelation in non-Gaussian error distributions (Dormann et al. 2007). We used the glmmPQL function (as suggested by Dormann et al. 2007) from the packages MASS (Venables and Ripley 2002) and nlme (Pinheiro et al. 2015) in R 3.2.2. (R Core Team 2015). Spatial GLMMs are based on penalized quasi-likelihood (PQL) and fit overall fixed effects with linear predictors containing random effects (group errors) and spatially autocorrelated within-group errors (nested structure) (Dormann et al. 2007). Spatial GLMMs account for both between and within site variability (using site as a random effect) while controlling for spatial autocorrelation between observations situated close to each other (using an exponential spatial correlation argument with $x$ and $y$ positions of quadrats) (Dormann et al. 2007; Kassahun et al. 2014). Owing to an excess proportion of zero values in ACPF abundance and richness, we used the two-part Hurdle model (Cunningham and Lindenmayer 2005; Potts and Elith 2006; Yesilova et al. 2010). The first part consists of a binomial model, which controls for the zero-inflation effect by indicating ACPF presence (positive counts) and absence (zero counts). The second part accounts for the over-dispersion effect by including only positive counts (truncated at zero) for ACPF abundance (negative binomial distribution, justified by variance $>$ mean, Potts and Elith 2006) and ACPF richness (Poisson distribution, justified by variance [approximately equal to] mean, Yesilova et al. 2010). We also performed the model with the presence of the five individual species (binomial distributions) for lakes where each species was present. As our objective was to quantify the influence of different habitat characteristics and not to develop a predictive model of species occurrence, we kept the full model. The model was limited to the first-order term (no interaction included) for practical and interpretation purposes.

[FIGURE 3 OMITTED]

Results

Landscape-scale habitat characteristics

Based on the results from the RDA ( $P$ value $=0.023$, Fig. 3 ), overall landscape-scale habitat characteristics influenced ACPF communities. Together, explanatory variables (watershed area, lake area, distance to shrub, slope, shoreline type) explained $57.6 \%$ of the total variance in the response variables (ACPF zone width, abundance, and richness); the first and second axes represented $39.9 \%$ and $17.7 \%$, respectively. Distance from the waterline to continuous shrubs was negatively correlated with transect slope. ACPF abundance and richness were positively correlated with each other, but there was no correlation between either of these components of ACPF communities and ACPF zone width. However, ACPF zone width was positively correlated with distance to shrub and negatively correlated with transect slope. ACPF richness was positively related to mineral shoreline, whereas the relationship between ACPF abundance and mineral shoreline was less pronounced. 


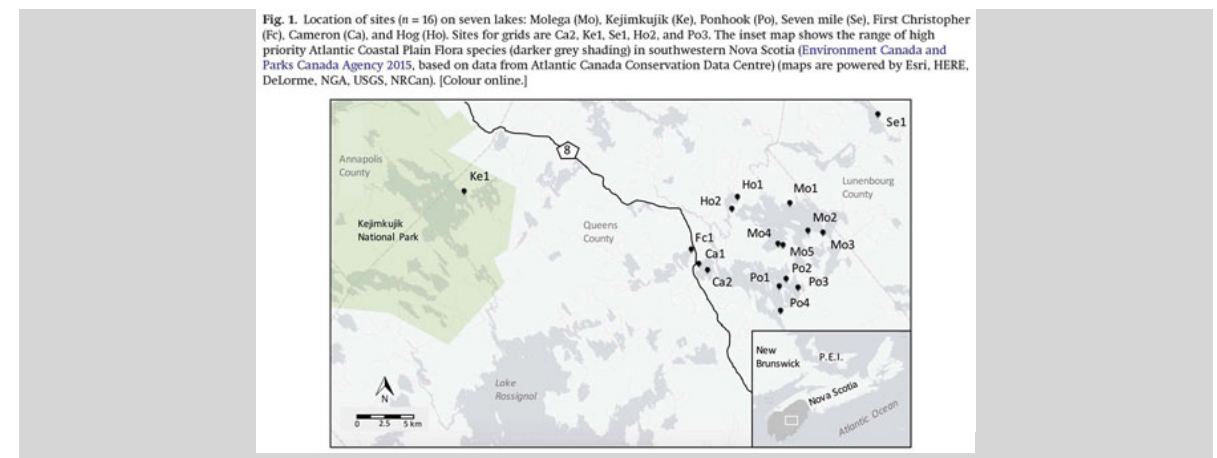

Local-scale habitat characteristics

As revealed by the spatial GLMMs, lower elevation, lower shrub cover, and greater sundew cover were significantly correlated with increased presence, abundance, and richness of herbaceous ACPF (Table 2; Fig. 4). Greater cover of graminoids was significantly correlated with increased ACPF presence and abundance, whereas greater bryophyte cover was only significantly correlated with increased ACPF abundance. The presence and abundance of ACPF was significantly higher in cobble, gravel, and organic substrates compared with boulder substrate (Fig. 5). The presence of a sand substrate had the greatest influence on ACPF abundance among all substrate types. No substrate type held a significantly higher ACPF richness than boulders.

Our assessment of interspecific habitat requirements among ACPF species (Table 3 ) showed that elevation was only negatively correlated with the presence of certain species, such as golden pert (Gratiola lutea Raf.), yelloweyed grass (Xyris difformis Chapm.), and redroot (Lachnanthes caroliniana (Lam.) Dandy). The influence was particularly pronounced for golden pert; its frequency declined by $11 \%$ for every centimetre in height from the waterline. Lower shrub cover was similarly correlated with the increased presence of redroot, lance-leaved violet (Viola lanceolata L.), and slender fragrant goldenrod (Euthamia caroliniana (L.) Greene ex Porter \& Britton). Quadrats with greater sundew cover were significantly correlated with the increased presence of all species except redroot, with the strongest influence on yellow-eyed grass (frequency increasing by $\sim 9 \%$ for every $1 \%$ gain in sundew cover). Greater cover of graminoids and bryophytes was significantly correlated with the increased presence of lance-leaved violet and slender fragrant goldenrod, respectively (but with a lower strength of association compared with sundew cover). Compared with a boulder substrate, cobble and gravel substrates were significantly correlated with the increased presence of lance-leaved violet, yellow-eyed grass (higher magnitude), and redroot, whereas organic substrate was significantly correlated with the increased presence of lance-leaved violet and redroot. The presence, richness, and abundance of herbaceous ACPF and the presence of all five species were not correlated with litter, woody material, or ferns.

[FIGURE 4 OMITTED]

[FIGURE 5 OMITTED]

Discussion

Weidentified influential habitat characteristics of herbaceous ACPF at the landscape scale, mostly in relation to shoreline topography, which influences the effects of hydrological disturbances, and thus nutrient availability and competitive interactions. We also related ACPF communities to local habitat characteristics, such as finer scale shoreline topographic attributes, substrate type, and the association or dissociation (e.g., competition) between different functional groups. In addition to characterizing habitat suitability of herbaceous ACPF as a group, we identified interspecific differences in the habitat requirements of individual ACPF species at the local scale.

Landscape-scale habitat characteristics

The width of the zone inhabited by ACPF on lakeshores was positively correlated with watershed area. By controlling the amount of surface water flowing into a water body, watershed area determines the riparian zone width by defining the high waterline from seasonal flooding (Hill and Keddy 1992; Sorrie 1994; Holt et al. 1995). Consequently, watershed area influences suitable habitat for many herbaceous ACPF, through flooding conditions, along with the slope of the shoreline (Morris et al. 2002). Accordingly, steeper slopes resulted in significantly lower ACPF zone width, which is likely due to a smaller area affected by hydrological disturbances (i.e., narrower riparian zone). Consequently, the riparian zone is usually defined by the first occurrence of shrubs species along the shoreline gradient (Hill and Keddy 1992), which marks the critical limit for less saturated conditions because long submersion periods prevent shrub establishment (Rhazi et al. 2006). Whereas ACPF are known to be mostly observed below that shrub zone (Wisheu et al. 1994), we can now state that the distance to shrubs appeared to be the most important factor explaining the width of the ACPF zone along the lakeshore-to-forest gradient. Distance from the waterline to shrubs could consequently be used as a proxy for the quantity of suitable habitat available for the establishment of ACPF, and also for any lakeshore plant species and communities (Schneider 1994).

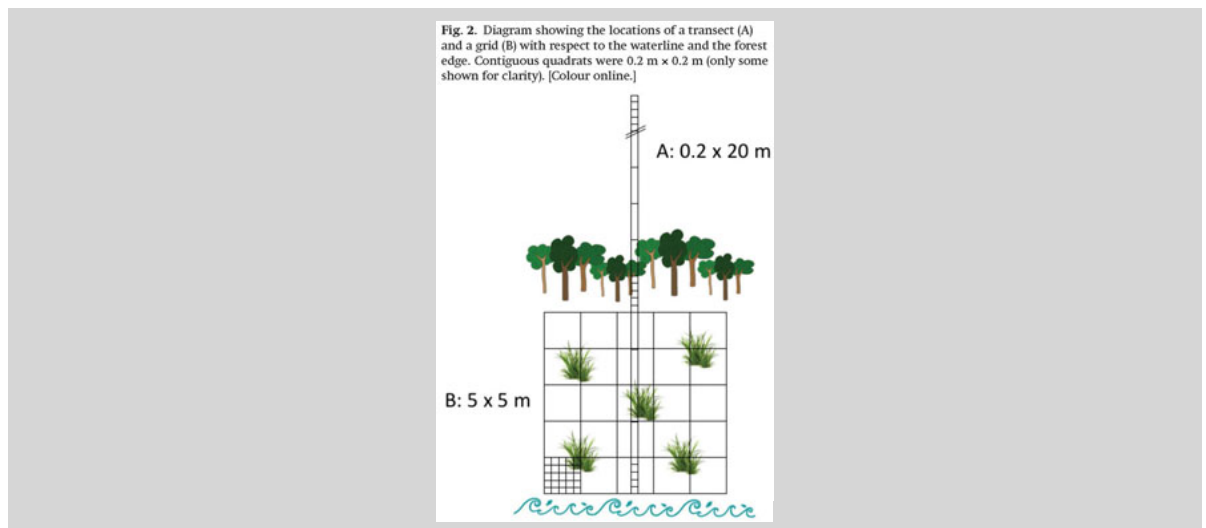

ACPF richness was significantly higher on mineral versus organic shorelines, perhaps due to interspecific interactions. Because wave action washes out fine sediments and nutrients, higher organic matter content on shorelines indicates the presence of lower intensity wave action (Wilson and Keddy 1986; Sorrie 1994; Holt et al. 1995). These organic shorelines 
provide more nutrients to sustain competitive species that can outcompete ACPF (Wilson and Keddy 1986; Wisheu and Keddy $1989,1994)$, consequently reducing ACPF richness. By assessing the statistical significance of the shoreline type, this key finding will better direct ACPF conservation efforts by prioritizing the protection of mineral shorelines over organic shorelines. This also has implications for other plant species that have broad environmental tolerances and poor competitive abilities found on lakeshores.

Local-scale habitat characteristics

At a local scale, lower relative elevation was strongly correlated with the presence, abundance, and richness of ACPF. Elevation influences many hydrological disturbances, such as the duration of flooding, the intensity and area affected by wave action and ice scouring, water depth, litter deposition, and organic matter content (Day et al. 1988). Consequently, elevation is a proxy for the frequency of hydrological disturbances and determines if individual growing positions are suitable for ACPF. The statistical significance of such fine scale change in elevation is a key finding of our study that highlights the importance of overall shoreline topography combined with finer-scale elevation.

Sundew, graminoid, and bryophyte species, appear to be influential local-scale habitat characteristics, as increases in their cover was correlated with increased presence, abundance, and (or) richness of herbaceous ACPF. Hydrological disturbances on lakeshores create areas free of competitive species, which makes them more suitable for stress-tolerant plants. Sundews, for example, have adapted to these low fertility ecosystems by obtaining their nutrients from an external source (Wilson and Keddy 1986). Ice scouring and wave action are known to contribute to high plant diversity on lakeshores by carrying seeds and seedlings, including graminoids species (Naiman et al. 1988); panic grasses (Panicum sp.), sedges, rushes, and bulrushes are commonly found on sandy lakeshores in Nova Scotia (Sweeney and Ogilvie 1993). As bryophytes are often found in moist-towet terrestrial environments, several moss species are found with ACPF communities (Environment Canada and Parks Canada Agency 2015). Consequently, sundews, graminoids, and bryophytes could be used as indicators of suitable habitat for many herbaceous ACPF, whereas only sundews (which had the strongest influence) have been previously mentioned as indicators of infertile soil and suitable ACPF habitat (Wisheu and Keddy 1989, 1994; Wisheu et al. 1994). These significant associations between ACPF communities and other functional groups of plants emphasizes the importance of considering the surrounding vegetation when defining species' ecological requirements.

Unlike these positive associations between ACPF species and other functional groups of plants, shrub cover was negatively correlated with ACPF presence, abundance, and richness. The presence of shrubs is a major biotic control on understory plant and herbaceous communities (Pabst and Spies 1998). Shrub height and cover can negatively affect herbaceous species diversity within lakeshore plant communities (Holt et al. 1995). Our quantification of very fine scale shrub cover summed at different heights confirms that lower shrub cover is an important biotic characteristic of suitable habitat for many herbaceous ACPF.

Although hydrological disturbances are known to generate litter heterogeneity (Naiman and Decamps 1997) and remove organic material (Day et al. 1988; Holt et al. 1995), the cover of litter and woody material did not show

a significant influence on ACPF communities and were consequently considered as less important factors of ACPF habitat suitability. However, the influence of hydrological disturbances is also reflected in the different substrate types. As lakeshores with higher levels of wave action are shaped by coarser and infertile substrates (e.g., low organic matter, silt, and clay content) (Keddy 1985; Wisheu et al. 1994), many ACPF species have been observed on sand or gravel shorelines with some peat patches (Keddy and Sharp 1994). Accordingly, we found that cobble, gravel, sand, and organic substrates were positively correlated with the presence and abundance of ACPF. Intermediate-sized substrates (cobble and gravel) were preferred when compared with large-sized substrates (stone and boulder). Whereas ACPF inhabit areas with diverse substrates, the preferred substrate type varies greatly depending on the species (as suggested by Sweeney and Ogilvie 1993).

By evaluating interspecific differences in habitat preferences of the five most common herbaceous ACPF included in this study, we observed that different ACPF species preferred different substrates. Golden pert and slender fragrant goldenrod were not influenced by substrate type, whereas the other three species were more commonly found on cobble, gravel, and (or) organic substrates. For species that were commonly found near the waterline (golden pert and yellow-eyed grass), only lower elevation and sundews were associated with their presence; even shrub cover, which generally has an important influence on ACPF species, was not correlated with the presence of these two species, suggesting that elevation has a critical role in their distribution. Although elevation was not an important habitat characteristic for all species, every species distribution pattern included elements of the surrounding vegetation, suggesting its importance in characterizing species habitat.

Using a multiscale approach was useful in discerning how different components of ACPF communities (e.g., zone width, presence, abundance, and richness) were influenced by different factors. First, landscape-scale habitat characteristics were important for determining the quantity of suitable habitat available for herbaceous ACPF. Second, the richness of ACPF communities was only influenced by substrate at a shoreline level, whereas substrate at a local scale could not be related to the richness of ACPF. Third, in contrast to factors affecting ACPF richness, ACPF abundance on shorelines was not influenced by landscape-scale habitat characteristics, but only by local-scale habitat characteristics (i.e., elevation, substrate, vegetation elements). Furthermore, shrub distribution and abundance influenced most components of ACPF communities at both the landscape scale (ACPF zone width) and the local scale (ACPF presence, abundance, and richness). Finally, studying individual species allowed us to assess different patterns of habitat requirements for ACPF.

Conclusions

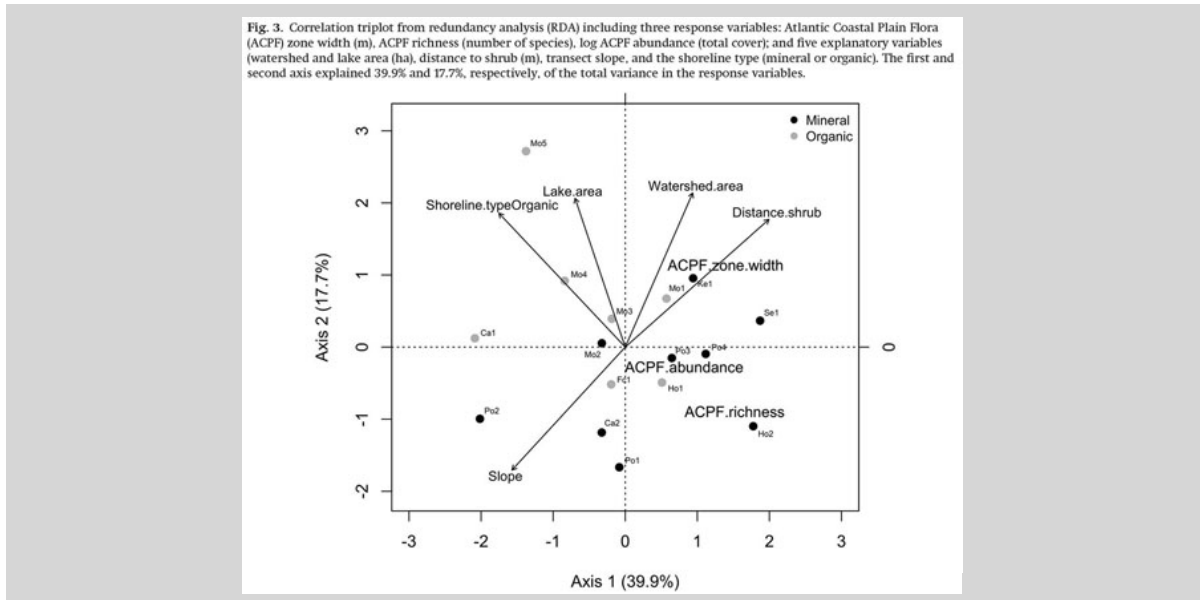

Although ACPF are a unique group of plants, they do exhibit stress tolerance, which is one of the three evolutionary plant 
strategies defined by Grime (1977). Stress-tolerant species are often considered as rare or endangered because of their poor competitive abilities, which restrict their expansion and (or) abundance. Consequently, understanding the characteristics that result from the stress and disturbance processes on which they rely will allow us to better manage and conserve their habitat. Habitat management is an essential component for the long-term conservation of ACPF populations in Nova Scotia (Wisheu and Keddy 1989). As ACPF individuals show high variability in their seasonal distribution in response to hydrological disturbance regimes, defining suitable habitat characteristics will allow us to identify potential habitat for ACPF species, even when they are not currently present. Furthermore, many suitable shorelines for ACPF are on small private land, making land tenure the greatest barrier to the protection of ACPF habitat (Sweeney and Ogilvie 1993; Wisheu et al. 1994). The identification of suitable local-scale habitat characteristics can especially be used by the public and conservation groups to better manage and protect potential habitat for ACPF. For example, gravel and cobble substrate, sundews, and graminoids, and low elevation positions on shorelines can refine the selection of potential habitats. Maintaining natural disturbance regimes and limiting nutrient runoff would allow ACPF to persist and colonize new shorelines in Nova Scotia (and within their North American range) by restricting shrub growth and maintaining low soil fertility. Our study highlights the importance of defining ecological requirements at both landscape and local scales to appropriately preserve habitat, which will benefit not only individual species but also plant communities.

Acknowledgements

We would like to thank Alain Belliveau for suggesting ACPF species, lakes, and sites; Amanda Ring and Brittany Gerhardt who helped to collect data; and Philip Giles and Yolanda Wiersma who provided suggestions on the manuscript. We also thank two anonymous reviewers for their valuable insight. Funding was provided by the Natural Sciences and Engineering Research Council of Canada, Saint Mary's University, Dalhousie University Biology Department, and the Government of Nova Scotia Labour and Advanced Education--Cooperative Education Incentive.

References

Clayden, S.R., Munro, M.C., Blaney, C.S., and Vander Kloet, S.P. 2010. Vascular flora of the Atlantic Maritime Ecozone: some new perspectives. In Assessment of species diversity in the Atlantic Maritime Ecozone. Edited by D.F. McAlpine and I.M. Smith. NRC Research Press, Ottawa, Ont., Canada. pp. 197-213.

Climate Canada. 2015. Temperature and Precipitation Chart for 1981 to 2010 Canadian Climate Normals Bridgewater. Available from

http://climate.weather.gc.ca/climate_normals/results_1981_2010_e.html?stnID=6308\&lang=e\&StationName=bridgewater\&SearchType=Contains\&stnNameSubmit=go\&dCode=4\&dispBack=1 [accessed April 2015].

Crowley, M., and Beals, L. 2011. Atlantic Coastal Plain Flora in Nova Scotia; Identification \& Information Guide. Mersey Tobeatic Research Institute.

Cunningham, R.B., and Lindenmayer, D.B. 2005. Modeling count data of rare species: some statistical issues. Ecology, 86(5): 1135-1142. doi:10.1890/04-0589.

Day, R.T., Keddy, P.A., McNeill, J., and Carleton, T. 1988. Fertility and disturbance gradients: A summary model for riverine marsh vegetation. Ecology, 69(4): 1044-1054. doi:10.2307/1941260.

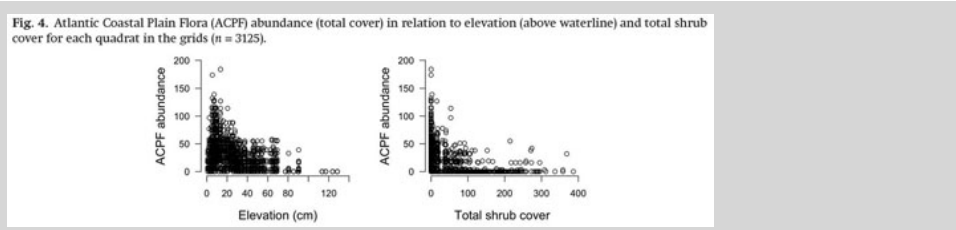

Dormann, C.F., McPherson, J.M., Araujo, M.B., Bivand, R., Bolliger, J., Carl, G., Davies, R.G., Hirzel, A., Jets, W., Kissling, W.D., Kuhn, I., Ohlemuller, R., Peres-Neto, P.R., Reineking, B., Schroder, B., Schurr, F.M., and Wilson, R. 2007. Methods to account for spatial autocorrelation in the analysis of species distributional data: a review. Ecography, 30: 609-628. doi:10.1111/j.2007.0906-7590.05171.x.

Environment Canada and Parks Canada Agency. 2015. Amended Recovery Strategy and Management Plan for Multiple Species of Atlantic Coastal Plain Flora in Canada [Proposed]. Species at Risk Act Recovery Strategy Series. Environment Canada and Parks Canada Agency. Ottawa.

Francis, G., and Munro, N. 1994. A biosphere reserve for Atlantic Coastal Plain Flora, southwestern Nova Scotia. Biol. Conserv. 68: 275-279. doi:10.1016/0006-3207(94)90416-2.

Grime, J.P. 1977. Evidence for the existence of three primary strategies in plants and its relevance to ecological and evolutionary theory. Am. Nat. 111(982): 1169-1194. doi:10.1086/283244.

Hill, N.M., and Keddy, P.A. 1992. Prediction of rarities from habitat variables: coastal plain plants on Nova Scotian lakeshores. Ecology, 73(5): 1852-1859. doi:10.2307/1940036

Hill, N.M., Keddy, P.A., and Wisheu, I.C. 1998. A hydrological model for predicting the effects of dams on the shoreline vegetation of lakes and reservoirs. Environ. Manage. 22(5): 723-736. doi:10.1007/s002679900142. PMID:9680540.

Holt, T.D., Blum, I., and Hill, N.M. 1995. A watershed level analysis of the lakeshore plant community. Can. J. Bot. 73(4): 598-607. doi:10.1139/b95-063.

Kassahun, W., Neyens, T., Molenberghs, G., Faes, C., and Verbeke, G. 2014. Marginalized multilevel hurdle and zero-inflated models for overdispersed and correlated count data with excess zeros. Stat. Med. 33: 4402-4419. doi:10.1002/sim.6237. PMID:24957791.

Keddy, C.J., and Sharp, M.J. 1994. A protocol to identify and prioritize significant coastal plain plant assemblages for protection. Biol. Conserv. 68: 269-274. doi:10.1016/0006-3207 (94)90415-4. 
Keddy, P.A. 1984. Plant zonation on lakeshores in Nova Scotia: A test of the resource specialization hypothesis. J. Ecol. 72(3): 797-808. doi:10.2307/2259532.

Keddy, P.A. 1985. Wave disturbance on lakeshores and the within-lake distribution of Ontario's Atlantic coastal plain flora. Can. J. Bot. 63(3): 656-660. doi:10.1139/b85-082.

Keddy, P.A., and Reznicek, A.A. 1982. The role of seed banks in the persistence of Ontario's coastal plain flora. Am. J. Bot. 69(1): 13-22. doi:10.2307/2442827.

Kembel, S.W., and Dale, M.R.T. 2006. Within-stand spatial structure and relation of boreal canopy and understorey vegetation. J. Veg. Sci. 17: 783-790. doi:10.1111/j.1654-1103.2006.tb02501.x.

Keys, K., Neily, P., and Quigley, E. 2010. Forest ecosystem classification for Nova Scotia, part 2: soil types. Nova Scotia Department of Natural Resources, Renewable Resources Branch.

Maas, C.J.M., and Hox, J.J. 2005. Sufficient sample sizes for multilevel modeling. Methodology, 1(3): 86-92. doi:10.1027/1614-2241.1.3.86

Marchand, P., and Houle, G. 2006. Spatial patterns of plant species richness along a forest edge: What are the determinants? For. Ecol. Manage. 223: 113-124. doi:10.1016/j.foreco.2005.10.064

Mersey Tobeatic Research Institute. 2015. Database of Atlantic Coastal Plain Flora locations, habitat and habitat quality. Available from http://www.merseytobeatic.ca/projectsfreshwater-atlantic-coastal-plain-flora.php [accessed April 2015].

Moore, D.R., and Keddy, P.A. 1988. Effects of a water-depth gradient on the germination of lakeshore plants. Can. J. Bot. 66(3): 548-552. doi:10.1139/b88-078.

Morris, P.A., Hill, N.M., Reekie, E.G., and Hewlin, H.L. 2002. Lakeshore diversity and rarity relationships along interacting disturbance gradients: catchment area, wave action and depth. Biol. Conserv. 106: 79-90. doi:10.1016/S0006-3207(01)00231-2.

Naiman, R.J., and Decamps, H. 1997. The ecology of interfaces: riparian zones. Annu. Rev. Ecol. Syst. 28: 621-658. doi:10.1146/annurev.ecolsys.28.1.621.

Naiman, R.J., Decamps, H., Pastor, J., and Johnston, C.A. 1988. The potential importance of boundaries of fluvial ecosystems J. N. Am. Benthol. Soc. 7(4): 289-306. doi:10.2307/1467295.

Nilsson, C., and Wilson, S.D. 1991. Convergence in plant community structure along disparate gradients: are lakeshores inverted mountainsides? Am. Nat. 137(6): 774-790. doi:10.1086/285193.

Nova Scotia Department of Natural Resources. 2013. Forest Inventory--Geographic information Systems. Available from http://novascotia.ca/natr/forestry/gis/forest-inventory.asp [accessed April 2015].

Oksanen, J., Blanchet, F.G., Kindt, R., Legendre, P., Minchin, P.R., O'Hara, R.B., Simpson, G.L., Solymos, P., Stevens, M.H.H., and Wagner, H. 2015. vegan: Community Ecology Package. R package version 2.3-1. URL http://CRAN.Rproject.org/package=vegan [accessed April 2015].

Pabst, R.J., and Spies, T.A. 1998. Distribution of herbs and shrubs in relation to landform and canopy cover in riparian forests of coastal Oregon. Can. J. Bot. 76(2): 298-315. doi:10.1139/b97-174

Parviainen, M., Luoto, M., Ryttari, T., and Heikkinen, R.K. 2008. Modelling the occurrence of threatened plant species in taiga landscapes: methodological and ecological perspectives. J. Biogeogr. 35: 1888-1905. doi:10.1111/j.1365-2699.2008.01922.x.

Pinheiro, J., Bates, D., DebRoy, S., Sarkar, D., and R Core Team. 2015. nlme: linear and nonlinear mixed effects models. R package version 3.1-121. Available from http://CRAN.Rproject.org/package=nlme [accessed April 2015].

Potts, J.M., and Elith, J. 2006. Comparing species abundance models. Ecol. Model. 199: 153-163. doi:10.1016/j.ecolmodel.2006.05.025

R Core Team. 2015. R: A language and environment for statistical computing. R Foundation for Statistical Computing, Vienna, Austria. Available from https://www.R-project.org/ [accessed April 2015].

Rhazi, L., Rhazi, M., Grillas, P., and El Khyari, D. 2006. Richness and structure of plant communities in temporary pools from western Morocco: influence of human activities. Hydrobiologia, 570: 197-203. doi:10.1007/s10750-006-0180-6.

Rooney, R.C., and Bayley, S.E. 2011. Relative influence of localand landscape-level habitat quality on aquatic plant diversity in shallow open-water wetlands in Alberta's boreal zone: direct and indirect effects. Landsc. Ecol. 26: 1023-1034. doi:10.1007/s10980-011-9629-8. 
Schneider, R. 1994. The role of hydrological regime in maintaining rare plant communities of New York's coastal plain pondshores. Biol. Conserv. 68: 253-260. doi:10.1016/0006-3207(94) 90413-8.

Sorrie, B.A. 1994. Coastal plain ponds in New England. Biol. Conserv. 68: 225-233. doi:10.1016/0006-3207(94)90410-3.

Sweeney, S., and Ogilvie, R. 1993. The conservation of coastal plain flora in Nova Scotia. Maine Nat. 1(3): 131-144 doi:10.2307/3858236.

Venables, W.N., and Ripley, B.D. 2002. Modern applied statistics with S. 4th ed. Springer, New York. ISBN 0-387-95457-0.

von Behren, C., Dietrich, A., and Yeakley, J.A. 2013. Riparian vegetation assemblages and associated landscape factors across an urbanizing metropolitan area. Ecoscience, 20(4): 373-382. doi:10.2980/20-4-3635.

Weiher, E., and Keddy, P.A. 1999. Relative abundance and evenness patterns along diversity and biomass gradients. Oikos, 87: 355-361. doi:10.2307/3546751.

Williams, J.N., Seo, C., Thorne, J., Nelson, J.K., Erwin, S., O'Brien, J.M., and Schwartz, M.W. 2009. Using species distribution models to predict new occurrences for rare plants. Divers. Distrib. 15: 565-576. doi:10.1111/j.1472-4642.2009.00567.x.

Wilson, S.D., and Keddy, P.A. 1986. Species competitive ability and position along a natural stress/disturbance gradient. Ecology, 67(5): 1236-1242. doi:10.2307/1938679.

Wisheu, I.C., and Keddy, P.A. 1989. The conservation and management of a threatened coastal plain plant community in eastern North America (Nova Scotia, Canada). Biol. Conserv. 48: 229-238. doi:10.1016/0006-3207(89)90120-1.

Wisheu, I.C., and Keddy, P.A. 1994. The low competitive ability of Canada's Atlantic coastal plain shoreline flora: implications for conservation. Biol. Conserv. 68: 247-252. doi:10.1016/0006-3207(94)90412-X.

Wisheu, I.C., Keddy, C.J., Keddy, P.A., and Hill, N.M. 1994. Disjunct Atlantic Coastal Plain Species in Nova Scotia: distribution, habitat and conservation priorities. Biol. Conserv. 68: 217-224. doi:10.1016/0006-3207(94)90409-X.

Yesilova, A., Kaya, Y., Kaki, B., and Kasap, I. 2010. Analysis of plant protection studies with excess zeros using zero-inflated and negative binomial hurdle models. Gazi Univ. J. Sci. 23(2): 131-136.

Zuur, A.F., Leno, E.N., and Smith, G.M. 2007. Principal component analysis and redundancy analysis. In Analyzing ecologica data. Statistics for Biology and Health series. Edited by M. Gail, K. Krickeberg, J. Samet, A. Tsiatis, and W. Wong. Springer Science + Business Media LLC, New York. pp. 193-224.

Natasha Daze Querry, Xavier Bordeleau, Karen A. Harper, and Sean P. Basquill

N. Daze Querry and K.A. Harper. Department of Biology, Saint Mary's University, 923 Robie Street, Halifax, NS B3H 3C3, Canada.

X. Bordeleau. Department of Biology, Dalhousie University, 1355 Oxford Street, P.O. Box 15000, Halifax, NS B3H 4R2, Canada.

S.P. Basquill. Wildlife Division, Nova Scotia Department of Natural Resources, 136 Exhibition Street, Kentville, NS B4N 4E5, Canada.

Corresponding author: Natasha Daze Querry (email: natasha.daze.querry@gmail.com).

Received 5 October 2016. Accepted 24 December 2016

Table 1. Description of the Atlantic Coastal Plain Flora species examined in this study, including the scientific and common name, general habitat of the species, and the Nova Scotia general status (and one Species At Risk Act (SARA) status) (Crowley and Beals 2011).

Scientific name

Bartonia paniculata subsp. iodandra

(B.L. Rob.) J.M. Gillet

Euthamia caroliniana (L.) Greene ex Porter \& Britton

Gratiola lutea Raf.

Hypericum virginicum L

Lachnanthes caroliniana (Lam.) Dandy

Lycopodiella appressa (Chapm.)

Cranfill

Rhexia virginica L.

Sisyrinchium sp. (atlanticum E.P. Bicknell

and angustifolium Mill.)

Viola lanceolata L.

Xyris difformis Chapm.

Scientific name

Bartonia paniculata subsp. iodandra

(B.L. Rob.) J.M. Gillet

Euthamia caroliniana (L.) Greene ex

Porter \& Britton

Gratiola lutea Raf.

Hypericum virginicum L.

Lachnanthes caroliniana (Lam.) Dandy
Common name

Branched bartonia

(screwstem)

Slender (Carolina) fragrant

goldenrod

Golden pert

Virginia (marsh) St.

John's-wort Redroot

Southern bog clubmoss

Virginia meadow-beauty

Blue-eyed grass (eastern

and pointed)

Lance-leaved violet

Lakeshore yellow-eyed grass

General habitat

Peat/cobble lakeshore, bog

Sand/gravel lakeshore

Waterline of sand/gravel

lakeshore Lakeshore,

wetlands Peat/sand/gravel

lakeshore 


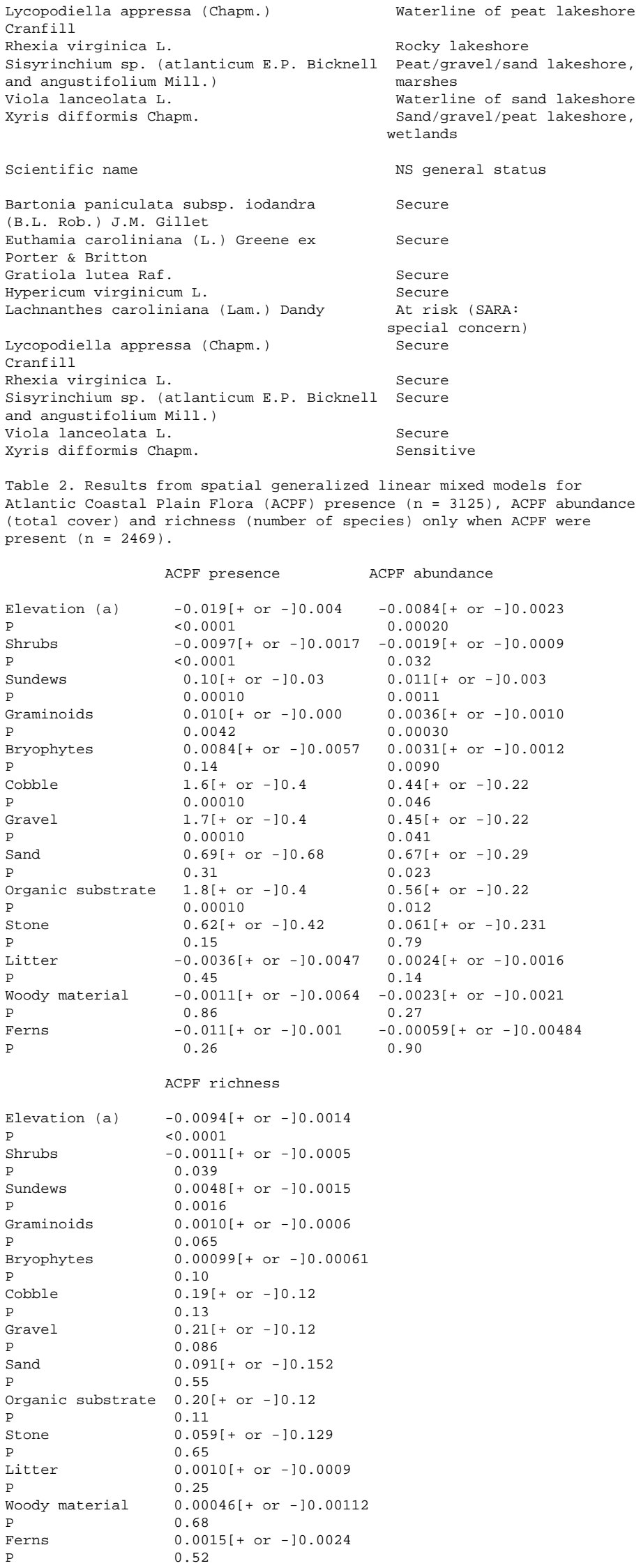

Note: Estimates of regression coefficients [+ or -] SE with P value of each explanatory variable. Values in bold font are statistically significant.

(a) Height in centimetres above the waterline.

Table 3. Results from spatial generalized linear mixed models for the presence of common Atlantic Coastal Plain Flora species in grids where the species was present $(\mathrm{n}=3125$ for lance-leaved violet, golden pert, and lakeshore yellow-eyed grass; $\mathrm{n}=2500$ for slender fragrant goldenrod; $\mathrm{n}=1875$ for redroot). 


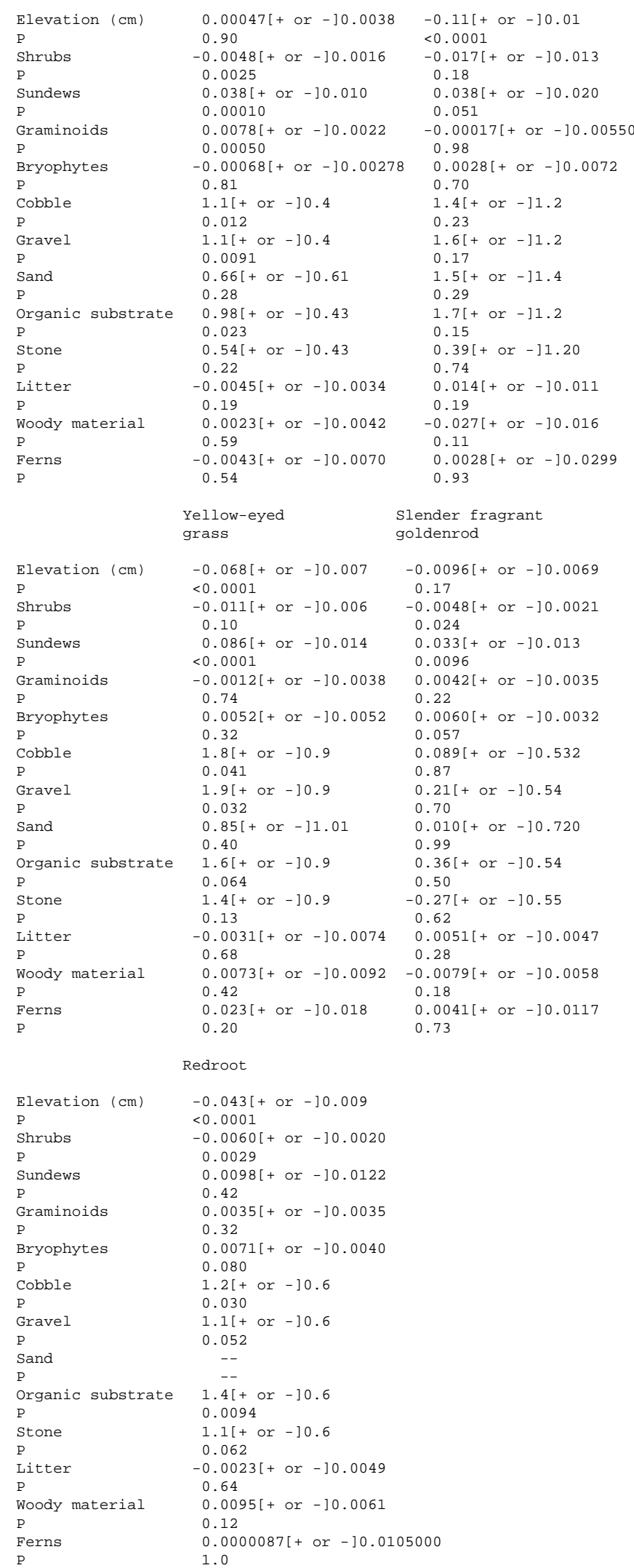

Note: Estimates of regression coefficients [+ or -] SE with P values. Values in bold font are statistically significant.

Copyright: COPYRIGHT 2017 NRC Research Press

http://www.nrc-cnrc.gc.ca/main_e.html 
Gale Document Number: GALE|A495742784 